Cape Hatteras, although some species extend beyond these limits. The centre section consists of 64 black-and-white and colour plates which are drawings of the species; the two end sections consist of descriptions of the species with notes on seasonal occurrence and where they are to be found. There is no attempt to divide the species within phyla. At the beginning of the book there are introductory chapters on how to use the book, nomenclature, collecting and preserving specimens, labelling, distribution and habits and zonation, and at the end a glossary. Such a book must be of limited use to collectors on British or European seashores, especially when goods books are already available (see Nature 264, 587, 1976).

David Bellamy is well known as a botanist-cum-broadcaster. His book Half of Paradise (Cassell: London; £7.95) bears no resemblance to the other two; it is a breezy and well illustrated account of two Joint Services underwater expeditions to the Chagos Archipelago in the Indian Ocean between 1972 to 1975 . They appear to have been a combination of a moderately serious scientific enterprise, a Services training exercise and for gathering material for a BBC documentary programme. Results were obtained on the growth of coral reefs, migration and breeding of seabirds and on the flora and fauna of the islands. The expedition charted the islands, dived on wrecks, had brushes with sharks and robber crabs, rats, mosquitoes and sand flies and generally had an eventful time. The book has a Foreword by Prince Charles, who clearly would have enjoyed being a participant. This is a book worth borrowing from the public library if one can 'take' David Bellamy's mildly irritating style of writing.

J.H.S. Blaxter

J.H.S. Blaxter is a Senior Principal Scientific Officer at the Dunstaffnage Marine Research Laboratory, Oban, Argyll, UK.

\section{Fish guides}

Two recent guides to British and European fishes could scarcely offer a greater contrast. Judging from their titles and general appearance, L. Cacutt's British Freshwater Fishes: The Story of their Evolution (Croom Helm: London, £6.95) is a serious and (one anticipates) authoritative study of the evolution and biogeography of Britain's freshwater fishes, Fishes: Freshwater and Marine Species (Chatto and Windus: London; paperback $£ 2.50$ ) second is slighter, being a collection of colour photographs with modest text fitted into matching spaces opposite the picture. One is written by a journalist professionally interested in fishes, the other by an Austrian ichthyologist and translated and adapted by an English zoologist. The first is pretentious, filled with errors and fails in its objective of presenting a coherent account of the fish fauna; the second is as authoritative as its appearance is modest.

Terofal's little book, a Chatto Nature Guide contains approximately 120 colour photographs of living fishes, mostly taken in aquaria. The standard of photography is high and the colour reproduction good. Most of the European freshwater fishes are included but the coverage of marine species is less good. Colour photographs of many of the Danubian species have not been reproduced before in English texts and this is a strong point in the book's favour. The text is organised in systematic order, and for each species included there are short, rather telegraphic, accounts under headings of, characteristics, distribution, habits, and diet, although the use of these headings is not consistent throughout. Errors are few; for example, the ninespined stickleback has been placed in the genus Pungitius for several years but is here referred to as Gasterosteus pungitius, and the photograph opposite the caption line, Molva molva, is of a torsk, Brosme brosme. Such minor errors apart, this is an excellent book and should help fill the stocking of many an angler this Christmas

- and probably those of quite a few ichthyologists also.

Of Cacutt's book I wish I could say the same. It starts with a typographical error on the fifth page of the prelims with "A fossile pike" a standard which continues more or less throughout. "Spiney-finned Fish" are referred to so often that I had to resort to a dictionary to check that it was not a permitted alternative for spiny.

The author's intention is said to be to present "the broad spectrum of the multimillion year-old story of Britain's freshwater fishes". There are also discussions of fossil fishes and some geology, and potted accounts of continental drift and of the ice ages, of which the last has some relevance to the subject. The major part of the book, however, is a collection of accounts, of British freshwater fishes, species by species, with heavy emphasis on anglers' interest in weights and records, and on behaviour.

The author's familiarity with the subject seem sketchy. On the interesting biogeography of the Irish freshwater fishes we are told on page 60 that the bream, loach

\section{Happiness is helical}

Two recently published books dealing with aspects of the study of molluscs, they are as different as roast beef and candy floss. Sea Shells: A Naturalist's and Collector's Guide (Phaidon: Oxford; $£ 6.50$ ), by Peter and Patricia Newell, is very pretty; it has a saccharin sweetness about it and it will appeal to shell novices. But such a diet cannot satisfy for long. Although this book contains many colour pictures by famous invertebrate specialists like Douglas P. Wilson and Heather Angel, the captioning is poor. The information given is sometimes inaccurate (the beautiful nudibranch illustrated on page 23 is not even correct to the nearest family), and the provenance of the specimens illustrated is not uniformly helpful. The text is undistinguished and there is on page 42 a "Key to the most and rudd are indigenous to Ireland and then on page 128 that the bream was introduced, while on page 110 the rudd is omitted from another list of indigenous species. In fact, none are indigenous to that island. The author shows a positive genius for getting terms and names wrong, for example, andronomous for anadromous, Roderick Imprey Murchison for R. Impey Murchison, and Erythrophthalmus scardinius for Scardinius erythrophthalmus. This trait provides a little light relief in places as on page 12 where Darwin's "Evolution of the Species" is described as a classic example of a "stodgy" scientific book, "sheer drudgery to read". Alas, Darwin wrote no such book.

This book certainly cannot be recommended, except perhaps as an example of the old saw that a little knowledge is a dangerous thing.

Alwyne Wheeler

Alwyne Wheeler works on fishes in the British Museum (Natural History), London, UK.

common classes of mollusks" which will confuse any budding shell expert; it should have been left out. Sea Shells is a pleasant coffee-table book, no more.

M.P. Kerney and R.A.D. Cameron's authoritative $A$ Field Guide to the Land Snails of Britain and North-west Europe (Collins: London; £5.50) in the Collins Field Guide series is the roast beef. It may require more effort to chew and swallow, but the nutritional benefits are substantial. This is the first compendium to deal comprehensively with the land snail shells of the whole of North-west Europe. There are, of course, fairly good guides in existence, dealing with the land molluscs of individual countries, but some of these are out of date, or so massive as to deter even the professional. The present guide describes and illustrates the 279 known species (plus a few stowaways which have turned up in greenhouses) in a way which will satisfy even the most demanding specialist; at the same time it can be used and enjoyed by 